\title{
Platform Thinking in Incumbent Firms: From Concept to Capability
}

\author{
Erik Leijon \\ AstraZeneca \\ erik.leijon@astrazeneca.com
}

\author{
Joanda Svenheden \\ Acando \\ joanda.svenheden@acando.com
}

\author{
Fredrik Svahn \\ Swedish Center for Digital Innovation \\ Department of Applied Information Technology \\ University of Gothenburg \\ fredrik.svahn@ait.gu.se
}

\begin{abstract}
Incumbent firms struggle with new forms of competition in today's increasingly digital environments. To leverage the benefits of innovation ecosystems they often shift focus from products to platforms. However, existing research provides limited insight into how firms actually implement this shift. Addressing this void, we have conducted a comparative case study where we adopt the concept of platform thinking to comprehend what capabilities incumbents need when engaging in innovation ecosystems and how those capabilities are developed.
\end{abstract}

\section{Introduction}

Many of the world's most valuable companies have made the leap from products to platforms [50]. Firms such as Apple, Google, and Amazon started as product-centric organizations, creating value by developing differentiated products for specific customer needs. Over the years, however, they have learned how to convert product users into platform users. They have also learned how to connect these users with third party actors, such as app developers, publishers, or advertisers. By charging fees for platform access they can now capture value from many different business transactions, rather than relying on a single revenue stream.

As firms shift focus from products to platforms they seek to take advantage of broad innovation ecosystems that turn suppliers and competitors into complementors and partners. Such a platform focus encourages "a new type of scope economies" in the sense of leveraging the "resources of other firms to help produce complementary innovations" [12, p. 292].

Clearly, this leap from products to platforms promises a great deal for incumbent firms. However, they face many challenges in implementing this shift; they must be able to attract different kinds of users [4], keep users in ecosystems [10], control the output from ecosystems [18], exploit complements [45], and continuously reconfigure the various resources offered to ecosystem stakeholders [13].

Existing research offers an increasingly detailed conceptual understanding of innovation ecosystem dynamics [17] and the central role of platforms in keeping ecosystems together [19, 33]. At the same time, it is argued that we must shed further light on how firms actually engage in innovation ecosystems, on what actions they take and what challenges they face [26]. Put differently, the research community calls for a better understanding of what particular capabilities are required [26, 27] and how these capabilities are developed $[19,40]$.

In this paper we adopt the concept of platform thinking to address this void in the literature. Combining contemporary platform literature and extant research on innovation ecosystems we develop a theoretical model of platform thinking, resting on eleven distinct capabilities. We then apply our model with the dual purpose to (1) demonstrate its value for understanding what capabilities incumbent firms need to develop, but also to (2) analyze how such capabilities are actually developed ${ }^{1}$.

Previous research underlines that the leap from products to platforms typically involves a leap into the digital [47]. This pulls off a clash between an established product innovation regime and an upcoming competing logic of digital innovation [21, 38], making the development of new capabilities complicated and risky. Therefore, to better understand how such competing concerns influence the emergence of new capabilities we have studied and compared four different firms in distinctly different industries.

\footnotetext{
${ }^{1}$ The authors wish to acknowledge that this research is supported by
} Acando by providing access to its extensive industry network. 


\section{Platform Thinking}

Our research departs from Sawhney's [36] original notion of platform thinking where the distinction between "core" and "derivatives" takes center stage. Given our focus on established firms making the leap from products to platforms, we view platform thinking as an approach where incumbents understand their core products as platforms that can be exposed to genuinely new innovation areas for generating complementary products and eventually new revenue streams. Synthesizing the innovation ecosystem literature and the platform literature we have identified four overarching dimensions that constitute platform thinking: stimulating value creation, capturing value, protecting value, and evolving ecosystem. We now present our theoretical framework, including key capabilities, and operationalizations (Table 1).

\subsection{Stimulate Value Creation}

In innovation ecosystems value creation is a collaborative process, resting on the success of multiple actors [2]. A focal actor - typically a platform owner - can stimulate such collaboration by promoting the overall health of the ecosystem [1], but also by actively engaging in co-creation to jointly create more value in the innovation ecosystem [1].

To stimulate value creation focal actors must develop capability to motivate non-focals to participate in the innovation ecosystem. Research recognizes intrinsic and extrinsic motivations [5]. Intrinsic motivations are non-tangible incentives, such as reputation, recognition, or intellectual challenge, while extrinsic motivations are external incentives, such as monetary compensations or future rewards. In platform ecosystems network effects make powerful extrinsic motivations. Direct network effects occur when increase in usage increases value for other users of the same type, while indirect network effects take place in multi-sided markets, where participation of one user group depends on the size of another user group [28]. Therefore, network effects may attract end-users by increased product diversity and complementors by a larger market. However, to trigger network effects and attract ecosystem participants a platform owner must ensure a sufficiently large installed base [19].

Contemporary research identifies another, increasingly important mechanism for focal actors as to stimulate ecosystem participation; providing boundary resources. By sharing their own resources focal actors can build a common identity across intersecting social worlds [37] and provide unique value in the ecosystem that non-focal actors are not able to create themselves [25]. In this vein, they can support complementors in their creative work by transferring design capability [46]. There are numerous examples of internal resources that a focal actor strategically can share with non-focal actors, such as know-how, equipment and technology, processes, data, $R \& D$ spillovers or access to delivery channels [1]. However, the concept is often used more specifically in reference to "software tools and regulations that serve as the interface for the arm's-length relationship between the platform owner and the application developer" [20, p. 174]. It is generally argued that boundary resources enable generativity by providing external actors capability to develop products or services without involvement from the platform owner [48].

While stimulation of value creation is a key element of platform thinking, research underlines that an innovation ecosystem will not gain enough momentum unless it becomes reasonably selfsustaining. Seeking such autonomy in the ecosystem, focal actors have to develop capability for establishing so called co-opetition. That is, structures rewarding relationships that simultaneously involve both competition and cooperation [7]. Collaborative structures set out to connect ecosystem participants, simplify interactions and lower transaction costs between them [25]. Such collaborative communities are able "to divide up design tasks via modular design architectures" [2, p. 1406], making them particularly skilled in resolving innovation problems that require cumulative knowledge [5]. By developing competitive markets focal actors allow themselves to pit innovators against each other to encourage more heterogeneous innovations as contributions can come from external actors in various settings. This way they do not bear any risk in the early innovation process as they only have to reward successful initiatives [5].

\subsection{Capture Value}

In contrast to value creation, value capture takes place on a firm-level and concerns how different actors restructure their competitive advantage and eventually reap profits from innovation ecosystems [34]. While the literature discusses several mechanisms to capture value from ecosystems, focal actors typically need to develop capabilities for deriving profit from transactions, spillovers, and new value propositions.

The opportunity to capture value from transactions materialize when the ecosystem constitutes a multisided market, where products or services that are controlled by the focal actor facilitate interaction between different groups of users [16].

Spillovers can be used to generate profit in two ways. First, focal actors may sell or out-license resources, intellectual property or information that are 
generated inside or outside the firm and that remains unused in relation to the focal actor's core offer [11]. However, a great deal of spillovers are early, immature innovations without an explicit market. Such spillovers may be brought to the market indirectly, as spin-off companies, or donated as spinouts to generate demand for other products that the donor continues to sell [45].

Finally, product diversity is a major asset in platform ecosystems, allowing incumbents to profit from new value propositions [6]. Beside additional direct revenue streams various complements may be used to increase the value of a firm's core products offer [45], but also to reduce risks associated with radical innovation [42]. When shifting from products to platforms firms often adopt hybrid business models to profit from existing core products while simultaneously engage in new value propositions [50].

\subsection{Protect Value}

A focal actor must continuously develop and exercise capabilities to protect the value created in its ecosystem. As such, it has to consider its own position, the ecosystem's boundaries, and the outcomes of ecosystem activities. In protecting its own position, a focal actor must restrict access to the platform by establishing effective governance mechanisms. Properly designed, such platform governance may "appropriately bound participant behavior without excessively constraining the desired level of generativity" [43]. Thereby it can be used to balance inherent ecosystem tensions, e.g. between control and autonomy or between collective and individual forces. If a focal actor tries to overexploit an ecosystem it will ultimately drain the ecosystem and risk its own competitiveness [25]. Hence, focal actors cannot just protect created value, but they also have to ensure a fair distribution of value across the ecosystem [9].

To protect ecosystem boundaries focal actors must fight envelopment attacks, where another platform provider seeks to enter the ecosystem by combining platforms [15]. They must also be proactive in preventing stakeholders from engaging in competing ecosystems [10] or in opportunistic behavior [34]. Ecosystem boundaries can be protected through lock-in effects, increasing switching costs [28]. Although lockin effects are effective in many situations, collaborative environments tend to fall apart if members are not confident that the focal actor will not exploit their contribution. Under those circumstances soft mechanisms, such as trust and relation building, may keep actors in the ecosystem and avoid opportunistic behavior [5, 34].

Finally, focal actors must protect innovation outcomes, created in the innovation ecosystem, from competing ecosystems. Although first mover advantages may put the focal actor ahead of competition, it is not a guarantee for sustainable competitive advantage [39]. Traditionally, legal mechanisms, such as contracts or patents guide innovation appropriability and protect innovations through exclusive access [34]. However, in a platform ecosystem selective revealing of intellectual property [24] may offer similar protection, without imposing legal protection mechanisms.

\subsection{Evolve Ecosystem}

Platform ecosystems are in constant change. To preserve competitive advantage over time focal actors must actively engage in the evolution of ecosystems and continuously reconsider how they stimulate, capture, and protect value. To keep creative momentum and ensure ecosystem competitiveness they must develop capabilities for expanding the ecosystem, securing appropriate incorporation mechanisms, and continuously improving platform performance.

As focal actors seek to expand ecosystems they often rely on options thinking, allowing them to identify, develop and realize new innovations without the obligation to invest further in an unfavorable innovation [35]. In this vein, options thinking offers a way to explore new ecosystem resources and actors, while spreading risk and keeping investments limited. When expanding an ecosystem focal actors must watch out for unstructured developments jeopardizing the firm's own position. Any growth strategy must therefore carefully balance between stability of the ecosystem and the need for new innovations [43].

To assist the evolution of an ecosystem focal actors also must invest in securing adequate incorporation mechanisms for integration of external innovations into their own internal processes [45]. This requires internal structures for securing the absorptive capacity of the firm [49]. In setting up such structures it has proved essential to invest in an open culture that encourages external collaboration [29, 11].

Finally, focal actors must continuously improve platform performance to preserve a central position as the ecosystem evolves. In doing so, they must pay attention to how boundary resources come into being and evolve. More precisely, they have to recognize that boundary resources are tuned in a temporally emergent and iterative change process, where the platform owner has a facilitative role. Boundary resources are not primarily designed by the firm that owns the platform infrastructure, but rather materialize from collisions between artifacts within and across multiple organizational and technological contexts [13]. Striving for improved platform performance, focal 
actors should seek to reduce complexity for innovators and support them in creating more specialized niches [19]. In doing so, they must scan the ecosystem for generic solutions, restructure them so that they can be re-utilized by innovators, and incorporate them in the platform. This process is referred to as the generalization and specialization of boundary resources [23].

Table 1 Theoretical Framework

\begin{tabular}{|c|c|c|c|}
\hline & Capability & Operationalization & Key References \\
\hline \multirow{4}{*}{ 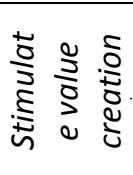 } & \multirow[t]{2}{*}{ Provide incentives } & Trigger network effects & Gawer and Cusumano [19] \\
\hline & & Provide boundary resources & Ghazawneh and Henfridsson [20] \\
\hline & \multirow{2}{*}{$\begin{array}{l}\text { Establish structures for } \\
\text { co-opetition }\end{array}$} & Develop collaborative communities & Baldwin and von Hippel [2] \\
\hline & & Develop competitive markets & Boudreau and Lakhani [5] \\
\hline \multirow{5}{*}{ 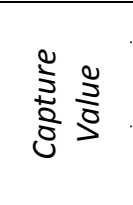 } & Profit from transactions & Facilitate transactions between user groups & Eisenmann, et al. [16] \\
\hline & \multirow[t]{2}{*}{ Profit from spillovers } & Out-license or sell spillovers & Chesbrough, et al. [11] \\
\hline & & Embrace spinoffs/spinouts & West and Gallagher [45] \\
\hline & \multirow{2}{*}{$\begin{array}{l}\text { Profit from new value } \\
\text { propositions }\end{array}$} & Exploit complements to reinforce core product & Boudreau [6] \\
\hline & & Adopt hybrid business models & Zhu and Furr [50] \\
\hline \multirow{6}{*}{ 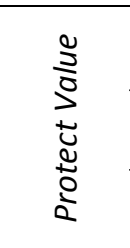 } & \multirow[t]{2}{*}{ Protect firm position } & Establish platform governance mechanisms & Wareham, et al. [43] \\
\hline & & Ensure even distribution of ecosystem resources & Cennamo and Santalo [9] \\
\hline & \multirow{2}{*}{$\begin{array}{l}\text { Protect ecosystem } \\
\text { boundaries }\end{array}$} & Establish lock-in mechanisms & Katz and Shapiro [28] \\
\hline & & Invest in trust and loyalty to the ecosystem & Ritala, et al. [34] \\
\hline & \multirow{2}{*}{$\begin{array}{l}\text { Protect innovation } \\
\text { outcomes }\end{array}$} & Exercise legal mechanisms & Teece [39] \\
\hline & & Implement selective revealing & Henkel, et al. [24] \\
\hline \multirow{6}{*}{ 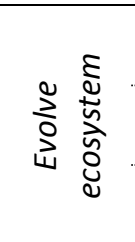 } & \multirow[t]{2}{*}{ Expand the ecosystem } & Adopt Options Thinking & Sambamurthy, et al. [35] \\
\hline & & Balance between stability and growth & Wareham, et al. [43] \\
\hline & \multirow{2}{*}{$\begin{array}{l}\text { Secure incorporation } \\
\text { mechanisms }\end{array}$} & Establish absorptive capacity & Zahra and George [49] \\
\hline & & Establish open culture and political will & Katz and Allen [29] \\
\hline & \multirow{2}{*}{$\begin{array}{l}\text { Enhance platform } \\
\text { performance }\end{array}$} & Tune boundary resources & Eaton, et al. [13] \\
\hline & & Ensure generalization and specialization & Henfridsson, et al. [23] \\
\hline
\end{tabular}

\section{Research Design}

In this research we have made a comparative case study [8] to generate theory [14] within the field of platform thinking. We adopted this design to analyze the social phenomena of platform thinking across different settings and with the ambition to generate more general research [3]. Searching for cases we identified four dominant Swedish industries: media, automotive, pharmaceutical, and retail. These industries were selected based on their polar positions (in terms of industry characteristics and innovation prerequisites $^{2}$ ) to ensure a diverse sample [14]. Within these industries, the twenty largest firms made our sampling frame. One organization in each industry was selected to exemplify incumbents within that particular category [8]: AutoCorp, a global car manufacturer, MediaCorp, a major national TV station, StoreCorp, a food retailer with national coverage, and PharmaCorp, a global pharmaceutical company.

Interviews were the main data source in our comparative case study. Searching for respondents we initially used LinkedIn and identified candidates on the basis of formal roles (Table 2). Trying to make sure that respondents were selected based on their relevance to understanding platform thinking in multiple contexts [8], they were required to have managerial positions within Innovation/R\&D, Business development, or Digitalization/IT. All in all, we conducted, recorded and transcribed 18 interviews, each lasting one hour.

Table 2 Respondents

\begin{tabular}{|c|c|}
\hline AutoCorp & StoreCorp \\
\hline IT Dir. (A1) & Business Strategy Dir. (S1) \\
\hline Innovation Manager (A2) & IT Manager (S2) \\
\hline Service Manager (A3) & Digital Strategist (S3) \\
\hline Strategy Dir. (A4) & Business Strategist (S4) \\
\hline MediaCorp & PharmaCorp \\
\hline $\begin{array}{l}\text { Business Development Dir. } \\
\text { (M1) }\end{array}$ & $\begin{array}{l}\text { Open Innovation } \\
\text { Manager (P1) }\end{array}$ \\
\hline Business Developer (M2) & IT Strategist (P2) \\
\hline Digital Strategist (M3) & Patent Advisor (P3) \\
\hline Business Strategist (M4) & Innovation Manager (P4) \\
\hline Product Strategist (M5) & Innovation Hub Manager (P5) \\
\hline
\end{tabular}

${ }^{2}$ Based on the Industry Classification Benchmark, icbenchmark.com 
The software Nvivo was used to code and analyze the empirical material. We applied a set of coding rules, derived from our theoretical framework, and employed check-coding throughout the coding process [31]. After the initial coding the empirical material was thematized to establish a rich understanding of emergent platform thinking among the studied firms.

\section{Results}

\subsection{Stimulate Value Creation}

The investigated firms all have something that naturally incentivize external actors, such as brand value, market reach or industry experience. Despite this, they often lack capability to reach out to external innovators. Being an R\&D company, PharmaCorp shares its research insights in the form of clinical compounds through an open innovation portal. These are resources that external researchers can use at no (or very low) cost to advance their own research. External actors can also get access to PharmaCorp's infrastructure to excel their innovation capacity and lower innovation barriers. AutoCorp provides temporary digital car keys to service providers, allowing them to deliver goods and provide services directly across AutoCorp's installed base of cars. This suggests that AutoCorp views the car as a platform for external innovation and the digital key as a boundary resource.

Sharing information and data is recognized as an area with huge potential. At AutoCorp there is an initiative where its cars share information on road conditions to authorities to improve traffic information. MediaCorp has arranged hackathons, centered on consumer behavior data. These initiatives clearly reflect emerging platform thinking but at the same time, respondents across the studied firms agree it is difficult to identify what information to share.

Turning to structures for co-opetition, PharmaCorp utilizes a competitive market by pitting external actors' ideas or research against each other in innovation challenges. Winning contributions are offered financial awards or partnerships. All four incumbents have also established physical and digital spaces where they collaborate with external actors. PharmaCorp has used its open innovation portal to create a collaborative community for scientists. The rest of the studied firms run workshops to provide capability for collaboration with external actors. The respondents describe that external actors are happy to join these initiatives even without financial compensation as they get to meet new people, learn new things and solve problems together. "Those are the incentives, you don't get anything specific out of it other than, hopefully, a widened perspective and new ideas" (M1). Although these workshops mimic collaborative communities, they tend to be one-off events rather than ongoing efforts. Consequently, while referring to ecosystems, most collaborations are still done in traditional customer-supplier relations "We are definitely part of an ecosystem but it is not really an even relationship. We are the client and they are suppliers" (S1).

\subsection{Capture Value}

AutoCorp's initiative with in-car deliveries, based on a digital key, is a recently developed example where platform thinking offers capability to derive profits from transactions. In this initiative AutoCorp connects drivers and service providers, while charging service provider for the opportunity to deliver goods to cars. The studied incumbents also try to develop capabilities for profiting on spillovers. StoreCorp recently started to exploit customer data and sell it to suppliers. The challenge lies in turning the large volumes of raw data to insights. A respondent from StoreCorp argued that "the least of our problems is if we will be able to charge the suppliers [...] this is information that we have and they want" (S1). PharmaCorp commercialized some of its spillovers as it out-licensed clinical compounds and created spin-off ventures from unused innovations. Still, the main objective of exploiting spillovers is to strengthen innovation capacity by allowing PharmaCorp "to access people with unique expertise that we may not have within the organization. That's difficult to put a price on" (P1). PharmaCorp and AutoCorp also try to increase brand value by sharing clinical compounds and information on road conditions.

Each of the studied firms have developed complements to strengthen their core value proposition. AutoCorp has developed a new infotainment platform that is included when customers purchase a larger entertainment package. StoreCorp has complemented its core offer by adding new in-store services, such as health check-ups and coffee shops. MediaCorp extend its content on social media, which increases the consumption of core services and PharmaCorp can strengthen its core value by developing digital solutions related to their medicines. Altogether, this indicates emerging platform thinking as StoreCorp, MediaCorp and PharmaCorp increasingly view the store, the media content and the pill as platforms to which complementary services can be developed.

Furthermore, the investigated incumbents recognize that they have to develop hybrid business models as traditional approaches are challenged by digitalization. MediaCorp tries to realize complementary profits from digital products so they can ensure "a digital business that's large enough when the core business totally 
drops" (M5). Smaller revenue streams that were once overlooked are now becoming increasingly important. However, the studied incumbents' core businesses still generate large profits, preventing a shift in behavior: "We want to protect the core business and sell cars rather than go into the unknown where you don't know how anything is going to play out" (A3).

\subsection{Protect Value}

The four incumbents are not particularly concerned about competition from non-traditional actors, but generally see different ecosystems as opportunities for collaboration. Despite these optimistic reflections, some of the respondents are uncertain about how their firm's position might change due to digitalization. As a response to this, some of the studied firms tend to move away from collaborations altogether: "we develop the complementary services in house and own the platform and the web shop ourselves" (M1).

Furthermore, all firms consider it essential to strategically select whom to share their resources with. PharmaCorp has governance mechanisms in place for judging the relevance and feasibility of collaborations: "we only initiate collaborations with researchers that we are confident have the ability to achieve what they set out to do" (P4). The respondents also indicate that they have established switching costs and lock-in effects in different ways. StoreCorp relies on a strong customer loyalty program, providing capability to protect its ecosystem, and MediaCorp ensures loyalty by providing niche content for the Swedish market.

AutoCorp suggest that its first-mover position in digital keys may protect it from competition. At PharmaCorp there is a strong focus on ecosystem relations built on trust, providing the firm "an advantage the day we are looking for a partner. We have already seen that it pays off and that is just pure decency, not a requirement we put on them [the external innovators]. [...] It is a result of trust, good relations and goodwill from both parties" (P5). The determination to create strong informal relations implies emerging platform thinking as the respondents realize that protecting innovations through legal means might not always maximize the value gain. Even so, PharmaCorp and AutoCorp are the only ones explicitly arguing investments in trust offers capability to protect value. Generally, the studied incumbents rely heavily on legal mechanisms to protect their innovations.

\subsection{Evolve Ecosystem}

All four incumbents have established separate innovation units that are disconnected from the core business. In doing so, they have developed capability for continuous exploration of external innovation environments. MediaCorp and PharmaCorp make small investments in initiatives and innovations that might not be profitable today but could offer new sources of value in the future. At StoreCorp the employees experiment with new technologies to learn for future projects. The IT Manager underlines that such activities are difficult to legitimize in an incumbent firm: "Sometimes I have to do an inverted business case and ask: how much will it cost to not do this? It will cost us an enormous amount of money, we will have a slow start and we will have to spend a lot of money in six months just to catch up" (S2). These initiatives indicate emerging platform thinking as the incumbents utilize options thinking to invest in opportunities that have an uncertain outcome but provide a variety of options in the future.

The studied firms also set out to establish arenas for long-term cross-fertilization between external and internal innovation. The most prominent example is PharmaCorp's launch of an innovation hub where small companies can collaborate with one another and with the incumbent. The hub has allowed PharmaCorp's employees to interact with external companies and regularly exchange knowledge. There are also structures for the hub management to revise what boundary resources they share with the external actors in order to further enhance their innovative capacity. Over time, this arena has proved highly supportive in the integration of external innovations. Even though there are some further examples of similar initiatives among the other incumbents, most firms demonstrate flaws in absorptive capacity and open culture. Being aware of these weaknesses, they all tried to build a more positive attitude towards external innovation by repeatedly presenting successful innovation initiatives.

However, one large challenge to overcome among the studied firms is that they currently develop a majority of the complementary innovations in-house or in traditional supplier relations. At the same time, the studied incumbents lack sufficient resources to identify and act on the opportunities necessary to keep up a competitive pace of innovation. The innovation hub seems to have overcome some of these problems as it entails generative characteristics by providing a foundation for external innovators: "We might have a theoretical idea that if we mix [competence] $A$ with $B$ we will get something awesome. Unfortunately, we cannot prioritize that but what we can do is to put two such companies next to each other and see what happens [...] As a result we have seven companies that have established formal collaborations with each other" (P5). 
Table 3 Evidence of platform thinking at PharmaCorp (P), AutoCorp (A), StoreCorp (S), and MediaCorp (M).

\begin{tabular}{|c|c|}
\hline \multirow[t]{2}{*}{ 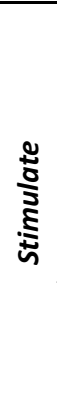 } & $\begin{array}{l}\text { Provide incentives } \\
\text { - Shared clinical compounds to enable further innovations by external actors (P) } \\
\text { - Shared consumer data in workshops to generate new ideas (M) } \\
\text { - Shared information on road conditions do drive innovation around the connected car }(\mathrm{A}) \\
\text { - Offered access to connected cars by sharing a digital key with service providers }(\mathrm{A}) \\
\text { - } \quad \text { Offered partnerships or financial compensation to increase participation in innovation challenges (P) } \\
\text { - Provided access to advanced instruments to spur innovation in small companies (P) }\end{array}$ \\
\hline & $\begin{array}{l}\text { Establish structures for co-opetition } \\
\text { - } \quad \text { Provided physical and digital spaces for collaboration with external actors }(P, A, M) \\
\text { - } \quad \text { Established innovation challenges to engage external actors in the generation of problem solutions }(P)\end{array}$ \\
\hline \multirow{3}{*}{ 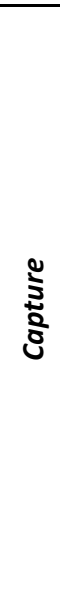 } & $\begin{array}{l}\text { Profit from transactions } \\
\quad \quad \quad \text { Charged service providers for in-car delivery of goods }(A)\end{array}$ \\
\hline & $\begin{array}{l}\text { Profit from spillovers } \\
\text { - Out-licensed compounds to external actors }(\mathrm{P}) \\
\text { - } \quad \text { Created spinoff ventures based on infant innovations }(\mathrm{P}) \\
\text { - } \quad \text { Increased innormation capacity by sharing clinical data to tap into the expertise of external researchers }(\mathrm{P}) \\
\text { - Increased brand value by sharing information on road conditions with public authorities }(\mathrm{A}) \\
\text { - Increased brand value by sharing insights from non-strategic areas with the academia }(\mathrm{P})\end{array}$ \\
\hline & $\begin{array}{l}\text { Profit from new value propositions } \\
\text { - Increased the effect of medicines by launching digital complements (P) } \\
\text { - } \quad \text { Enhanced driving experience by launching semi-open infotainment platform (A) } \\
\text { - } \quad \text { Introduced in-store health services and coffee shops to strengthen their marketplace (S) } \\
\text { - } \quad \text { Reinforced core services by providing additional content on social media (M) } \\
\text { - }\end{array}$ \\
\hline \multirow{3}{*}{ 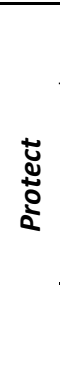 } & $\begin{array}{l}\text { Protect firm position } \\
\quad \quad \text { Established teams to evaluate collaborations with external actors }(P)\end{array}$ \\
\hline & $\begin{array}{l}\text { Protect ecosystem boundaries } \\
\text { - } \quad \text { Established informal relations with external actors based on trust }(\mathrm{P}) \\
\text { - } \quad \text { Sought first-mover advantages by establishing an innovation ecosystem around the digital key (A) } \\
\text { - } \quad \text { Established loyalty systems to increased switching costs by }(\mathrm{S}) \\
\text { - } \quad \text { Provided niche content to increase consumer loyalty }(\mathrm{M})\end{array}$ \\
\hline & $\begin{array}{l}\text { Protect innovation outcomes } \\
\text { - Relied on legal mechanisms to protect innovation outcomes }(P, A, S, M)\end{array}$ \\
\hline \multirow{3}{*}{$\underset{\mathrm{m}}{\mathrm{g}}$} & $\begin{array}{l}\text { Expand the ecosystem } \\
\text { - Established separate innovation units, disconnected from the core business }(P, A, S, M) \\
\text { - Invested in new business areas and technologies to explore future opportunities }(P, M) \\
\text { - } \quad \text { Experimented with new digital technologies to learn about trends and developments }(S)\end{array}$ \\
\hline & $\begin{array}{l}\text { Secure incorporation mechanisms } \\
\text { - Integrated start-up technology with existing digital services (A) } \\
\text { - } \quad \text { Placed employees in external companies to learn new practices and incorporate external knowledge (P) }\end{array}$ \\
\hline & $\begin{array}{l}\text { Enhance platform performance } \\
\text { - Introduced a practice for continuously reassessing what resources to share with external actors (P) } \\
\text { - Provided an innovation hub for co-creation of products and services (P) }\end{array}$ \\
\hline
\end{tabular}

\section{Discussion}

As summarized in Table 3, our comparative case study offers important insights into the manifestations of platform thinking in incumbent firms. By applying our theoretical model (Table 1) we have provided a portrait of what capabilities incumbents have to develop as they shift focus from products to platforms. Drawing on this empirical evidence, we now seek to discuss how such capabilities are developed.

\subsection{From Strategic Sourcing to Targeted Seeding}


To stimulate value creation in external ecosystems an incumbent firm must find ways to empower ecosystem actors by sharing various boundary resources [20] and setting up structures for ecosystem co-opetition [5]. Our study indicates that incumbents are generally well aware of requisite capabilities and potential rewards. At the same time, the comparative case study shows that such attempts to stimulate external value creation typically triggers substantial resistance, ranging from privacy and regulatory issues to identifying boundary resources and getting approval for sharing them. This resistance must be understood in relation to incumbents' established practices, where internal activities are coordinated by up-front specification of innovation outcomes. In this vein, the new initiatives uncovered a tension between internal and external collaboration [38, 33], as they forced the incumbents to move away from established internal practices. To develop capabilities for stimulating value creation the firms had to maneuver this fundamental tension. The four incumbents in this study all rely hard on traditional supplier relations, where goods and services are acquired on the basis of strategic sourcing. Therefore, to handle the tensions between internal and external from growing out of control, they often ended up with specialized ecosystem setups, such as PharmaCorp's sharing of clinical compounds, AutoCorp's digital key, or MediaCorp's hackathons. Although being open to unconventional and unexpected outcomes among external contributors, these initiatives were given a rather precise direction through specific staring conditions, reasonably well aligned with internal practices. This suggests that incumbents firms, to develop capabilities for stimulating value creation, should initially engage in targeted seeding where the scope of the ecosystem is intentionally limited.

\subsection{From Core Products to Related Complements}

To capture value from external ecosystems incumbents must look beyond existing business models and learn how to derive profits from transactions [16], exploit spillovers [11], and capitalize on radically new value propositions [6]. The incumbents in our study were well aware of this shift and realized that existing markets may transform at a pace where they do not have the time to react before they are obsolete [44]. Therefore, they persistently asked questions, such as; what if patients and hospitals demand to pay for outcomes, not medicines? What if drivers no longer want to own cars? What if customers buy a majority of groceries online? These questions triggered a shift in focus, from core products to yet unknown complements, with the potential to open up alternative revenue streams. As illustrated by AutoCorp's in-car delivery this, in turn, brought a strong focus on the process of innovation - separate from its outcome since the digital key became a boundary resource to be utilized by external actors. However, the emerging focus on innovation processes and generation of complements triggered resistance among incumbents since they all derive large profits from a core product. Insofar as investments are made in complements, it is traditionally viewed as a way to increase profits from that core. Therefore, to maneuver the structural tension between a product focus and a process focus [38], the incumbents tried to develop hybrid business models allowing for exploitation of multiple revenue streams, while still retaining revenue generated from their core businesses [27, 50]. MediaCorp's new channels for content distribution and PharmaCorp's digital complements for existing drugs illustrate that the incumbents typically tried to establish such hybrids by searching for options where existing business were not immediately threatened. This suggests that incumbents firms, to develop capabilities for capturing value, have to implement the shift from core to complements gradually by carefully identifying new revenue streams that resonate with, rather than challenge, existing business models.

\subsection{From Controlled Processes to Selective Recruitment}

Engagement with external innovation ecosystems force incumbent firms to develop capability for protecting its own position [43], ecosystem boundaries [28], and innovation outcomes [39]. The organizations in our study all recognized that external ecosystems, characterized by co-opetition [7], will underperform or die if managed on the basis of traditional control. In this context, key assets such as central store locations or advanced production processes would offer little protection and limited competitive advantage. In response, they launched initiatives such as PharmaCorp's innovation hub to rapidly build new ecosystem relations [24]. Other efforts, such as MediaCorp's initiative on providing niche content or StoreCorp's loyalty program, were specifically focused on the delicate issue of creating trust among ecosystem members [34]. Despite these emerging signs of platform thinking formal control, based on contracts, secrecy, and patents, was deeply anchored in organizational practices. Therefore, to develop capabilities for protecting value the firms had to strike a balance between their own need for control and ecosystem members' need for autonomy [43, 22, 38]. Rather than trying to resolve this tension by restricting 
autonomy within ecosystems, the incumbents focused on restricting entrance. The innovation hub and the ecosystem around the digital key are salient examples, where well known and respected market actors were selectively invited. This suggests that incumbents firms, to develop capabilities for protecting the ecosystem, should carefully choose whom to collaborate with by exercising selective recruitment of ecosystem members.

\subsection{From Long-Range Product Planning to Resource Orchestration}

For ecosystems to remain healthy over time, focal actors need to continuously expand its borders [43], secure incorporation mechanisms [49], and enhance platform performance [13]. The four incumbents in our study demonstrated a will to develop such a long-term agenda for continuous shaping of innovation environments: they invested in experimental technologies, explored options thinking, experimented with open platform solutions, and developed novel boundary resources. Often these progressive initiatives triggered resistance from the organization for the simple reason that they challenged existing organizational identity, centered on long-range product planning. Since identity becomes intertwined in routines, procedures, and beliefs it is often difficult to develop new requisite capability that is not consistent with existing capabilities [41, 38]. Addressing this tension between existing and requisite innovation capability the investigated incumbents often decided to establish independent innovation units, where they could freely explore new forms of innovation without direct impact on daily operations. PharmaCorp's innovation hub was probably the best illustration of how an incumbent can continuously enhance its performance through such an independent unit. In this case, the hub offered PharmaCorp capability to grow the ecosystem in a controlled manner and coordinate interactions between its members. The hub made a self-sustaining environment where different stakeholders were able to benefit from and contribute to a shared boundary resource base and use it to cocreate innovations. To remain attractive over time, PharmaCorp listened carefully to the needs of the external actors and continuously tuned thed boundary resources to improve the offer to external actors [13, 23] and enable generativity [20]. This typically meant that they transformed existing internal resources, such as equipment or knowledge, into accessible boundary resources. These resources could then be used by hub members in radically new ways without challenging the internal identity of PharmaCorp. This suggests that incumbents firms, to develop capabilities for evolving ecosystems, initially should seek to establish independent, yet close innovation environments. In such environments they can exercise continuous resource orchestration to build generative capacity and trigger new innovations, yet without challenging existing firm identity.

\section{Conclusions and Future Work}

This study contributes to the literature on platforms and innovation ecosystems by providing an answer to how incumbents can make the leap from products to platforms. It offers a theoretical model of platform thinking for better understanding what capabilities incumbent firms need to develop. Applying the model we then draw important conclusions on how such capabilities are actually developed. Our work suggests that the clash between established product innovation practices and an upcoming competing logic plays a critical role in how such capabilities emerge. We see an opportunity for future research to further uncover how tension and contradiction shape platform thinking. Such research could engage specialized theoretical framings, such as paradox [30] or ambidexterity [32].

\section{References}

[1] R. Adner, The wide lens: A new strategy for innovation, Penguin UK, 2012.

[2] C. Baldwin and E. von Hippel, "Modeling a Paradigm Shift: From Producer Innovation to User and Open Collaborative Innovation", Organization Science, 22 (2011).

[3] I. Benbasat, D. K. Goldstein and M. Mead, "The case research strategy in studies of information systems", MIS Quarterly, 11 (1987), pp. 369-386.

[4] V. M. Bennett and L. Pierce, "Motivation matters: Corporate scope and competition in complementary product markets", Strategic Manage J, 37 (2016).

[5] K. Boudreau and K. Lakhani, "How to Manage Outside Innovation", MIT Sloan Management Review, 50 (2009).

[6] K. J. Boudreau, "Let a Thousand Flowers Bloom? An Early Look at Large Numbers of Software App Developers and Patterns of Innovation", Organization Science, 23 (2012), pp. 1409-1427.

[7] A. M. Brandenburger and B. J. Nalebuff, Co-opetition, Crown Business, 2011.

[8] A. Bryman, Social research methods, Oxford university press, 2008.

[9] C. Cennamo and J. Santalo, "How to Avoid Platform Traps", MIT Sloan Management Review, 57 (2015).

[10] C. Cennamo and J. Santalo, "Platform competition: Strategic trade-offs in platform markets", Strategic Manage J, 34 (2013), pp. 1331-1350.

[11] H. Chesbrough, W. Vanhaverbeke and J. West, eds., Open Innovation: Researching a New Paradigm, Oxford University Press, USA, 2006. 
[12] M. A. Cusumano, Staying power: Six enduring principles for managing strategy and innovation in an uncertain world, OUP Oxford, 2010.

[13] B. Eaton, S. Elaluf-Calderwood, C. Sørensen and Y. Yoo, "Distributed Tuning of Boundary Resources: The Case of Apple's iOS Service System", MIS Quarterly, 39 (2015).

[14] K. M. Eisenhardt, "Building Theories from Case Study Research", Academy of Management Review, 14 (1989).

[15] T. Eisenmann, G. Parker and M. Van Alstyne, "Platform envelopment", Strategic Manage J, 32 (2011).

[16] T. Eisenmann, G. Parker and M. Van Alstyne, "Strategies for two-sided markets", Harvard Business Review, 84 (2006), pp. 92.

[17] O. A. El Sawy, A. Malhotra, Y. K. Park and P. A. Pavlou, "Research Commentary: Seeking the Configurations of Digital Ecodynamics: It Takes Three to Tango", Information Systems Research, 21 (2010), pp. 835-848.

[18] A. Gawer, "Bridging differing perspectives on technological platforms: Toward an integrative framework", Research Policy, 43 (2014).

[19] A. Gawer and M. A. Cusumano, "Industry Platforms and Ecosystem Innovation", Journal of Product Innovation Management, 31 (2014), pp. 417-433.

[20] A. Ghazawneh and O. Henfridsson, "Balancing Platform Control and External Contribution in Third-Party Development: The Boundary Resources Model", Information Systems Journal, 23 (2013), pp. 173-192.

[21] H. Godoe, "Innovation regimes, R\&D and radical innovations in telecommunications", Research Policy, 29 (2000), pp. 1033-1046.

[22] R. W. Gregory, M. Keil, J. Muntermann and M. Mähring, "Paradoxes and the Nature of Ambidexterity in IT Transformation Programs", Information Systems Research, 26 (2015), pp. 57-80.

[23] O. Henfridsson, L. Mathiassen and F. Svahn, "Managing Technological Change in the Digital Age: The Role of Architectural Frames", Journal of Information Technology, 29 (2014), pp. 27-43.

[24] J. Henkel, S. Schöberl and O. Alexy, "The emergence of openness: How and why firms adopt selective revealing in open innovation", Research Policy (2013).

[25] M. Iansiti and R. Levien, "Strategy as ecology", Harvard business review, 82 (2004), pp. 68-81.

[26] R. Kapoor and J. M. Lee, "Coordinating and competing in ecosystems: How organizational forms shape new technology investments", Strategic Manage J, 34 (2013).

[27] J. Karimi and Z. Walter, "The Role of Dynamic Capabilities in Responding to Digital Disruption: A FactorBased Study of the Newspaper Industry", Journal of Management Information Systems, 32 (2015), pp. 39-81.

[28] M. L. Katz and C. Shapiro, "Systems competition and network effects", The Journal of Economic Perspectives, 8 (1994), pp. 93-115.

[29] R. Katz and T. J. Allen, "Investigating the Not Invented Here (NIH) syndrome: A look at the performance, tenure, and communication patterns of $50 \mathrm{R} \& \mathrm{D}$ Project Groups", R\&D Management, 12 (1982), pp. 7-20.

[30] M. W. Lewis, "Exploring Paradox: Toward a More Comprehensive Guide", Academy of Management Review, 25 (2000), pp. 760-776.
[31] M. B. Miles and A. M. Huberman, Qualitative data analysis: An expanded sourcebook, Sage, 1994.

[32] C. A. O'Reilly Iii and M. L. Tushman, "Organizational Ambidexterity: Past, Present, and Future", Academy of Management Perspectives, 27 (2013), pp. 324-338.

[33] G. Parker, M. Van Alstyne and X. Jiang, "Platform Ecosystems: How Developers Invert the Firm", MIS Quart. (forthcoming).

[34] P. Ritala, V. Agouridas, D. Assimakopoulos and O. Gies, "Value creation and capture mechanisms in innovation ecosystems: a comparative case study", International Journal of Technology Management, 63 (2013), pp. 244-267.

[35] V. Sambamurthy, A. Bharadwaj and V. Grover, "Shaping agility through digital options: Reconceptualizing the role of information technology in contemporary firms", MIS Quarterly, 27 (2003), pp. 237-263.

[36] M. S. Sawhney, "Leveraged high-variety strategies: from portfolio thinking to platform thinking", Journal of the Academy of Marketing Science, 26 (1998), pp. 54-61.

[37] S. L. Star and J. R. Griesemer, "Institutional ecology,translations' and boundary objects: Amateurs and professionals in Berkeley's Museum of Vertebrate Zoology, 1907-39", Social studies of science, 19 (1989), pp. 387-420.

[38] F. Svahn, R. Lindgren and L. Mathiassen, "Embracing Digital Innovation in Incumbent Firms: How Volvo Cars Managed Competing Concerns", MIS Quart. (forthcoming).

[39] D. J. Teece, "Profiting from technological innovation: Implications for integration, collaboration, licensing and public policy", Research Policy, 15 (1986), pp. 285-305.

[40] A. Tiwana, B. Konsynski and A. Bush, "Platform Evolution: Coevolution of Platform Architecture, Governance, and Environmental Dynamics", Information Systems Research, 21 (2010), pp. 675-687.

[41] M. Tripsas, "Technology, Identity, and Inertia through the Lens of "The Digital Photography Company", Organization Science, 20 (2009), pp. 441-460.

[42] M. Tripsas, "Unraveling the process of creative destruction: Complementary assets and incumbent survival in the typesetter industry", Strategic Manage J, 18 (1997).

[43] J. Wareham, P. B. Fox and J. L. Cano Giner, "Technology Ecosystem Governance", Organization Science, 25 (2014), pp. 1195-1215.

[44] P. Weill and S. L. Woerner, "The Future of the CIO in a Digital Economy", MIS Quarterly Executive, 12 (2013).

[45] J. W. West and S. Gallagher, "Challenges of Open Innovation: The Paradox of Firm Investment in Open-Source Software", R\&D Management, 36 (2006), pp. 319-331.

[46] E. Von Hippel and R. Katz, "Shifting innovation to users via toolkits", Management Science (2002), pp. 821-833.

[47] Y. Yoo, R. J. Boland, K. Lyytinen and A. Majchrzak, "Organizing for Innovation in the Digitized World", Organization Science, 23 (2012), pp. 1398-1408.

[48] Y. Yoo, O. Henfridsson and K. Lyytinen, "Research Commentary: The New Organizing Logic of Digital Innovation: An Agenda for Information Systems Research", Information Systems Research, 21 (2010), pp. 724-735.

[49] S. Zahra and G. George, "Absorptive capacity: A review, reconceptualization, and extension", The Academy of Management Review, 27 (2002), pp. 185-203.

[50] F. Zhu and N. Furr, "Products to Platforms: Making the Leap", Harvard Business Review, 94 (2016), pp. 72-78. 